\title{
Recent trends on the stent research for blood arteries by bibliometric analysis
}

\author{
Sejung Ahn ${ }^{1}$, Jung-Suk Sung ${ }^{2}$, Brad $\mathrm{Choi}^{3}$, Hackjoo Kim$^{4}$ and Yong Kiel Sung ${ }^{4^{*}}$
}

\begin{abstract}
The research trends on stent for blood arteries are reviewed by bibliometric analysis using 7,790 journal articles published from 1986 to 2013 of the Web of Science database. The bibliometric indicators are applied to analyze the journal article data, which are simple number of publications for selecting key players, citation indicators for measuring qualitative research performance, collaboration indicators for figuring out the degree of international collaboration and keyword mapping for identifying the research trends. The studies of stent for blood arteries are investigated on the basis of the analysis by countries, institutions and topic changing. The leading countries and institutions published many high-quality journal articles with strong international collaboration. In this report, the current status and future of research trends are clearly revealed from the periodic topic changing analysis. The keywords such as 'drug eluting stent', 'stent coated with new polymers' and 'drug delivery systems' have come into the recent stent-related research, which means lots of efforts are under way to overcome the present limitations of the research.
\end{abstract}

Keywords: Stent, Blood artery, Drug-eluting stent, Blood coagulation, Biomaterials

\section{Introduction}

A stent is a small mesh tube to be used to treat weak and narrow arteries. Normal arteries are blood vessels that are able to carry blood away from heart to other parts of human body. However, problems occur sometimes in the arteries of old or sick people. In the case of good chance, a stent is placed in an artery as part of a procedure called percutaneous coronary intervention (PCI). PCI restores blood flow through narrow or blocked arteries of the body. A replaced stent helps support the inner wall of the artery within a certain period of time for few months or years after putting on PCI.

Some stents are coated with polymeric drugs that are slowly and continuously released into the artery. The stents are called drug-eluting stents (DES). Introducing DES, several problems have been reduced dramatically in coronary artery stenting by limiting long-term efficacy [1]. The medicine helps prevent the artery from coming blocked again. Recently, researches have

\footnotetext{
* Correspondence: yksung@dongguk.edu

${ }^{4}$ ReSEAT, Korea Institute of Science and Technology Information, 66 Hoegi-ro, Seoul 130-741, Dongdaemun-gu, Korea

Full list of author information is available at the end of the article
}

indicated that the reduction in restenosis might have been obtained at the expense of a higher incidence of stent thrombosis, particularly late stent thrombosis [2].

In the present paper, recent progress has been reviewed on the stent coating for heart blood arteries of human body. The research trends of the stent coating for heart blood arteries are reviewed using 7,790 journal articles published from 1986 to 2013 in various aspects.

\section{Review}

The journal articles for analysis were collected using search query made of keywords using Web of Science (WoS) database provided by Thomson Scientific (Philadelphia, PA, USA). The used search query was shown in Table 1. The dataset contains Science Citation Index (SCI) and SCI-Expanded (SCIE) with a document type limited to the 'article' reflecting the accurate R\&D trends and the search period was set to $1986 \sim 2013$. The basic analysis was carried out using the COMPAS (COMPetitive Analysis System) developed by KISTI (Korea Institute of Science and Tech- 


\begin{tabular}{ll}
\hline Search query & Limitation \\
\hline TS $=($ stent* and ((bio* near/3 stent*) or "biodegradable polymer*" or "biocompatible polymer*" or & PY = 1986 2013 document type = 'article' \\
"biocompatible materia*" ${ }^{* \prime}$ "biomaterial*" or anti-coagulant* or "biomedical coating" or "biomedical & \\
implant*" or "drug-eluting" or "drug elut*" or "drug delivery coating system")) & \\
\hline
\end{tabular}

nology Information) and VantagePoint ${ }^{\circ}$ provided by Search Technology, Inc. The VOSviewer of CWTS and Netminer 4.0 provided by Cyram are used for the network analysis.

Figure 1 shows the number of publications by the year of $1986 \sim 2013$. The annual number of journal articles since 1986 increases steadily in spite of a little fluctuation between 2000 and 2002. However, the accumulative number of publications gradually increases. We can estimate the technology growth level by curve fitting to a suitable model. In this case, the accumulative data are able to be explained by a logistic model. In a logistic model, the general expression for the technology growth level can be written as $[3,4]$.

$$
y=\frac{L}{1+\alpha e^{-\beta t}}
$$

where $L$ is an upper limit of technology growth, $t$ means time and the coefficients $\alpha$ and $\beta$ are the parameters which determine the shape of the growth curves.
We can estimate the year of inflection point to 2015.3 by the fitting curve as shown in the inset of Figure 1, which means the current research on stent being in the midst of active time.

In order to investigate the stent-related research trends by the authors of countries, we have extracted county information from addresses of author-affiliation. The researches on stents have been performed by 71 countries from 1986 to 2013. Figure 2 shows a share of number of publications of top-10 countries which take a share about $74 \%$ of the total publications. USA ranks the first with 2,586 papers and Germany (1,122), Italy (833), China (575), Netherlands (547), South Korea (517), UK (484), Japan (461), France (406), and Canada (352) are come along after USA. The annual number of publications for the whole countries generally increases as shown in Figure 3.

The research performance should be considered quantitatively as well as qualitatively. If the simple number of publications is used as a quantitative indicator, the widely known indicator for research quality

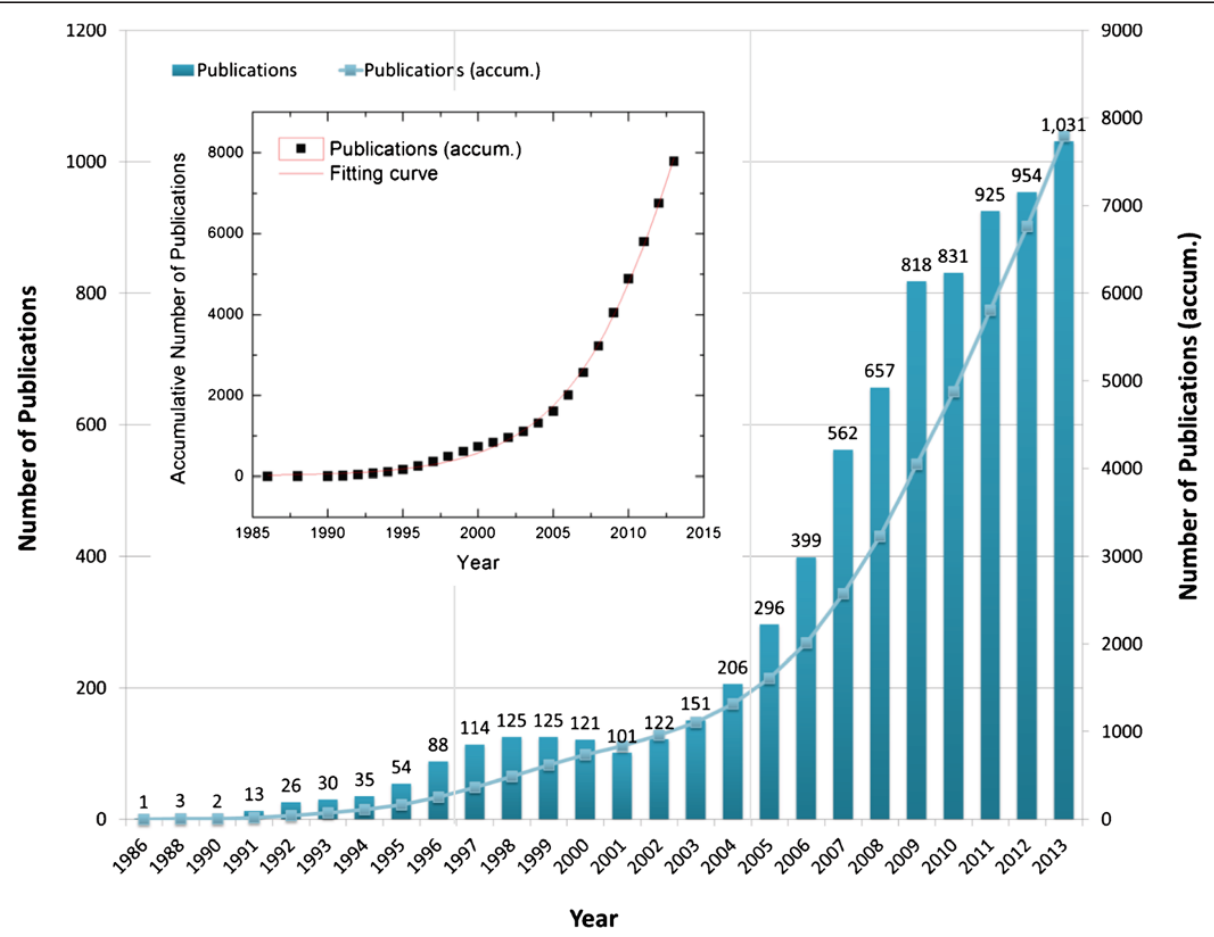

Figure 1 The number of publications on stent by year; The fitting curves of accumulative number of publications (inset). 


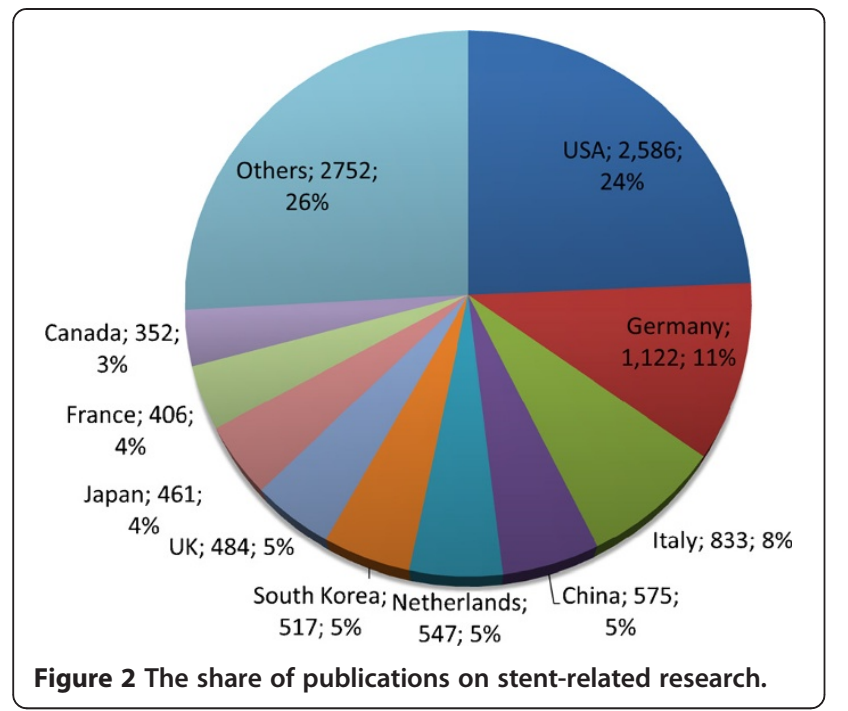

measurement is based on citation. Here, we have used the quality-factor(Q-factor), which is defined as the average number of citations per publication $(C P P)$ of a country compared to the world-wide average $C P P$ in a given research field [5]. It could be regarded that the research level is over world average level when the Qfactor is more than 1 . The Netherlands shows 1.64 as the highest Q-factor and Canada (1.45), UK (1.39), France (1.31), USA (1.23), Italy (1.15) and Germany (1.14) show the values over 1 .
The collaboration network analysis between countries has been investigated. USA collaborates with 57 countries including Germany, Italy, the Netherlands, Canada, France, UK, and South Korea on stent-related research. Figure 4 shows the international collaboration network of top-21 countries publishing more than 100 papers. The width of lines means the strength of collaboration and the size of nodes represents the number of publications of the country. We can find that research on stent has been performed and developed by building strong collaboration between USA and other countries in Europe. Table 2 shows the summary of quantitative and qualitative indicator-values for top-10 countries of the stent-related research. Figure 5 shows the scatter chart to see the relation between $\mathrm{Q}$-factor and number of publications and the size of circles refers the number of collaborations.

In a view of institution, about 5,000 institutions published the stent-related journal articles. Table 3 shows the status of top-20 institutions. Columbia University in USA published 214 papers and Cardiovascular Research Foundation (202), Harvard University (202), Erasmus University Medical Center (199) and Washington Hospital Center (153) published over 150 papers. Many of institutes are collaborating with each other for a research on stent. Thus, we have used the international collaboration strength (ICS) indicator which is obtained by 'the share of foreign institutions collaborating with a

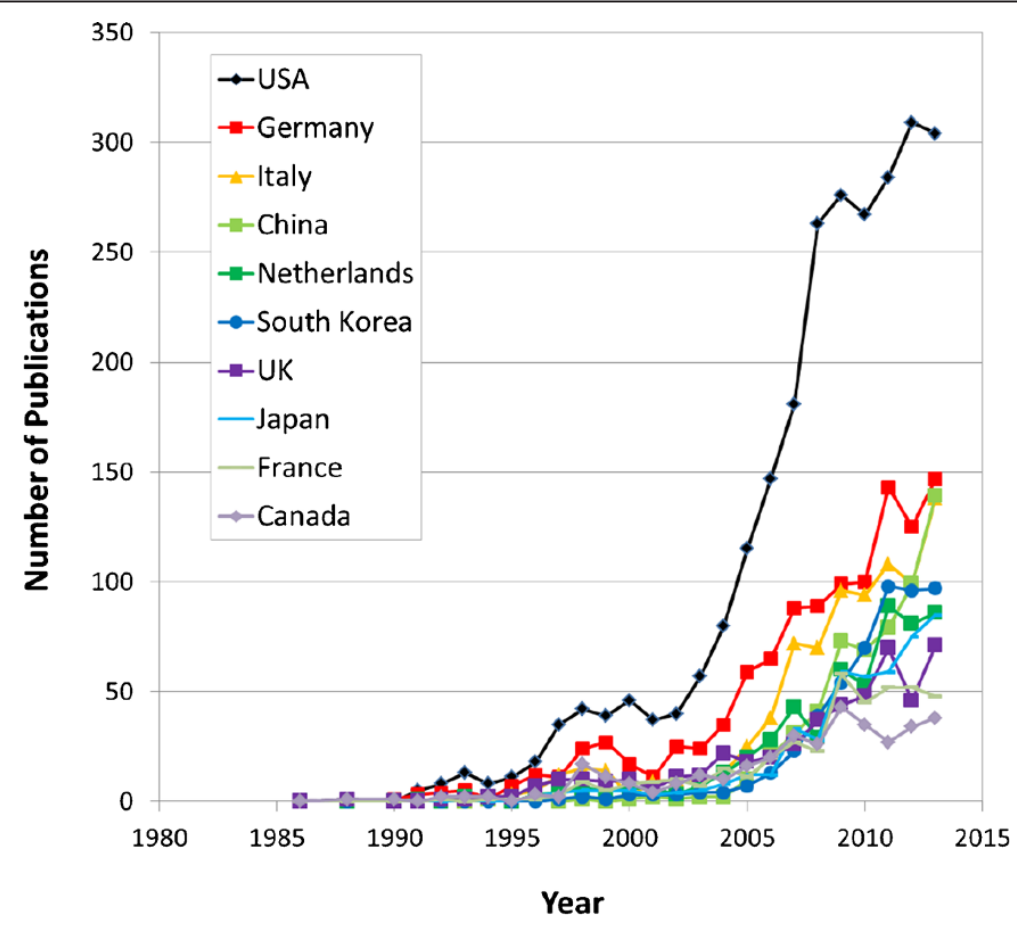

Figure 3 Annual number of publications on stent by year of top-10 countries. 


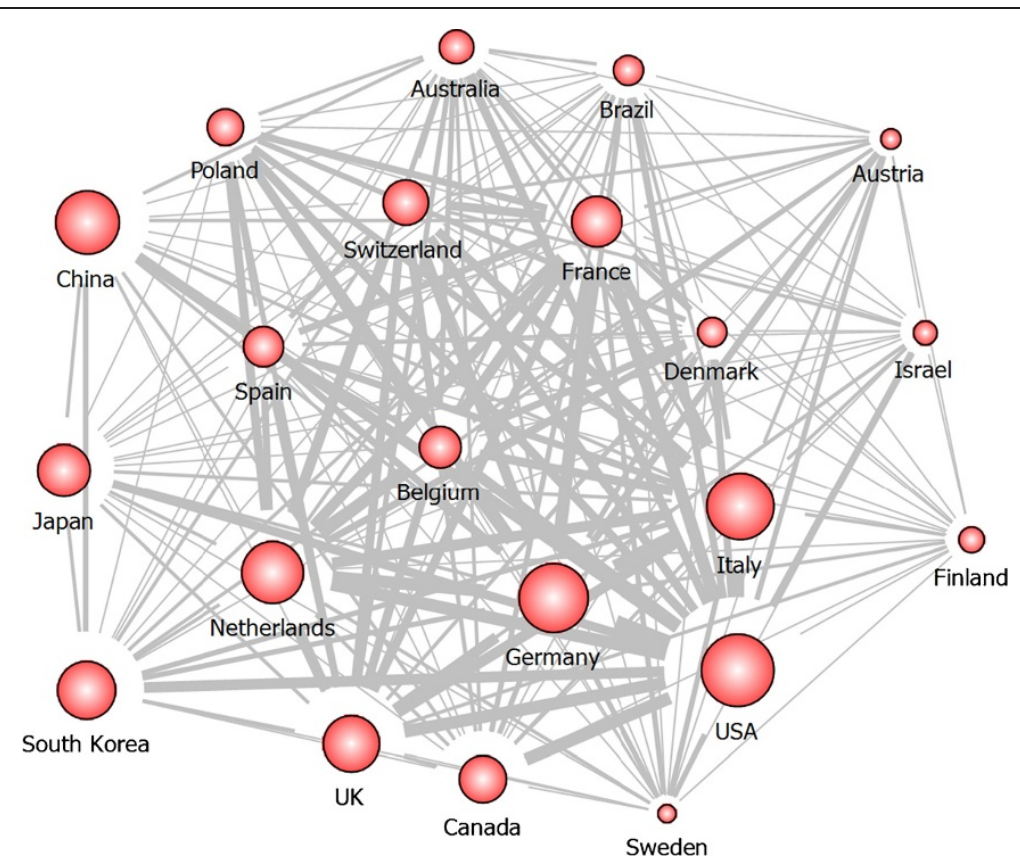

Figure 4 Collaboration network map among top-21 countries.

certain institution in its total collaborating'. Similar to the Q-factor, the field-averaged ICS is defined as the Lfactor. As a same rule for the Q-factor, an institution is said to be at the field average when its $L$-factor is equal to unit [5]. Figure 6 shows the relationship of $Q-L$ values of the top-20 institutions. As shown in the Figure 6, the plot is divided into four sections by the guide-line ( $Q=1$ and $L=1$ ). The institutions in the Section I have high quality and high international network where almost the whole top-20 institutions are belonging. The institutions in Section III (Seoul National University, Yonsei University and Shanghai Jiao Tong University)

Table 2 Quantitative and qualitative indicators for top-10 countries of the stent-related research

\begin{tabular}{lcccc}
\hline Countries & No. of pub. & CPP & Q-factor & No. of collab. \\
\hline USA & 2586 & 23.24 & 1.23 & 57 \\
Germany & 1122 & 21.67 & 1.14 & 48 \\
Italy & 833 & 21.88 & 1.15 & 43 \\
China & 575 & 7.03 & 0.37 & 25 \\
Netherlands & 547 & 31.02 & 1.64 & 41 \\
South Korea & 518 & 14.69 & 0.77 & 28 \\
UK & 484 & 26.26 & 1.39 & 41 \\
Japan & 461 & 12.22 & 0.64 & 31 \\
France & 406 & 24.88 & 1.31 & 44 \\
Canada & 352 & 27.50 & 1.45 & 33 \\
\hline
\end{tabular}

show low performance and relatively domestic network though large publication outputs.

Meanwhile, the research trends can be understood in a view of topic changing. The visualization technique by the co-word mapping is widely used to identify knowledge structure in a certain research field. In the present study, keywords given by authors are used with the VOSviewer software, which suggests the combination

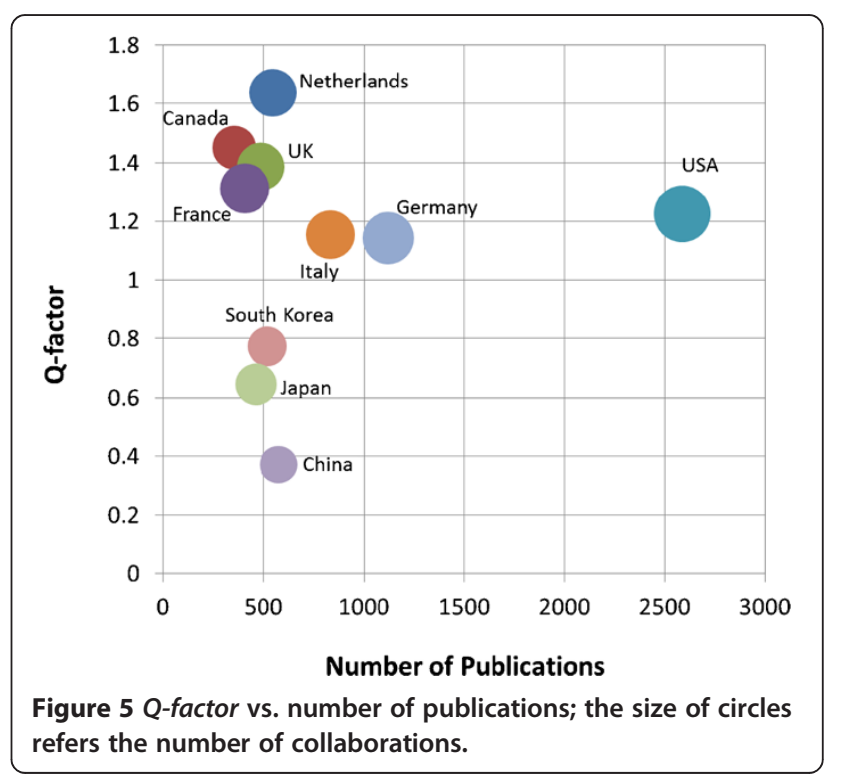


Table 3 The top-20 institutions in the field of stent research

\begin{tabular}{|c|c|c|c|c|c|c|}
\hline Institution & Country & No. of pub. & CPP & Q & $\mathbf{L}$ & Section \\
\hline Columbia Univ. & USA & 214 & 29.94 & 1.58 & 2.42 & I \\
\hline Cardiovasc Res Fdn. & USA & 202 & 27.58 & 1.45 & 2.34 & I \\
\hline Harvard Univ. & USA & 202 & 31.95 & 1.69 & 1.87 & 1 \\
\hline Erasmus MC & Netherlands & 199 & 23.62 & 1.25 & 2.67 & I \\
\hline Washington Hosp Ctr. & USA & 153 & 28.33 & 1.49 & 1.18 & I \\
\hline Univ. Ulsan & South Korea & 146 & 23.99 & 1.27 & 1.28 & 1 \\
\hline Boston Sci Corp. & USA & 136 & 33.36 & 1.76 & 2.44 & I \\
\hline Cleveland Clin Fdn. & USA & 133 & 39.02 & 2.06 & 1.85 & 1 \\
\hline Seoul Natl Univ. & South Korea & 132 & 13.87 & 0.73 & 0.95 & III \\
\hline Brigham \& Womens Hosp. & USA & 129 & 48.69 & 2.57 & 1.91 & । \\
\hline Mayo Clin. & USA & 124 & 32.58 & 1.72 & 2.30 & 1 \\
\hline Yonsei Univ. & South Korea & 119 & 13.82 & 0.73 & 0.75 & III \\
\hline Tech Univ. Munich & Germany & 112 & 43.08 & 2.27 & 1.93 & I \\
\hline Ctr.Cuore Columbus & Italy & 104 & 43.34 & 2.29 & 2.09 & I \\
\hline Univ. Hosp Bern & Switzerland & 104 & 41.46 & 2.19 & 2.81 & I \\
\hline Duke Univ. & USA & 102 & 37.61 & 1.98 & 1.65 & I \\
\hline Stanford Univ. & USA & 101 & 24.95 & 1.32 & 2.20 & I \\
\hline Mt Sinai Med Ctr. & USA & 98 & 24.31 & 1.28 & 2.24 & I \\
\hline Univ. Toronto & Canada & 79 & 33.70 & 1.78 & 1.76 & 1 \\
\hline Shanghai Jiao Tong Univ. & China & 75 & 8.31 & 0.44 & 0.88 & III \\
\hline
\end{tabular}

algorithm of mapping and clustering by intuition. Here, the period is divided into 3 parts. Figures 7,8 and 9 shows the density view of keyword map based on the co-occurrence matrix by periods. The color of the point in a map represents the density of the point depending

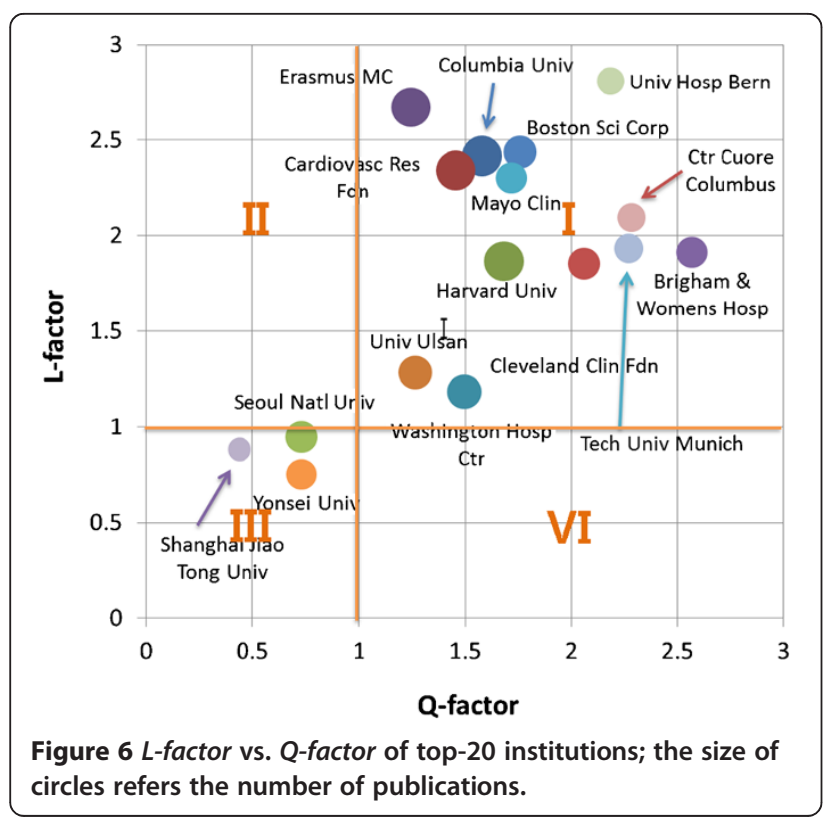

on the number of neighboring items and on the weights of these items. The color of point with the larger number of neighboring items of a point and the higher weights of neighboring items is to be red. Consequently, the opposite case is to be blue. Also, the font size of the item's label depends on the weight of the item which is determined by the appearance frequency. And the location of the words reflects the Euclidean distances between all pairs of items [6].

The Period I during first 10 years from 1986 to 1995 is the beginning stage. As shown in Figure 7, the words such as 'stent', 'restenosis', 'biocompatible' are appeared with a few frequencies. The Period II (1996 2005) could be regarded as a time of differentiation. Figure 8 shows that the number of keywords are rapidly increased and diversified as the advances of research on stent. The remarkable keywords are 'coronary artery disease', 'drug eluting stent', 'thrombosis', 'inflammation', 'drug-coated stent', and so on. Period III (2006 2013) is called as the time of expansion and stabilization. As seen in Figure 9, 'drug eluting stent' is emerging as a main topic of stent-related research and keywords such as 'paclitaxel', 'sirolimus', 'drug delivery', 'zotarolimus', 'everolimus biodegradable polymer', 'endothelial function' stand out as being representative words. We are able to know that many efforts are under way to 


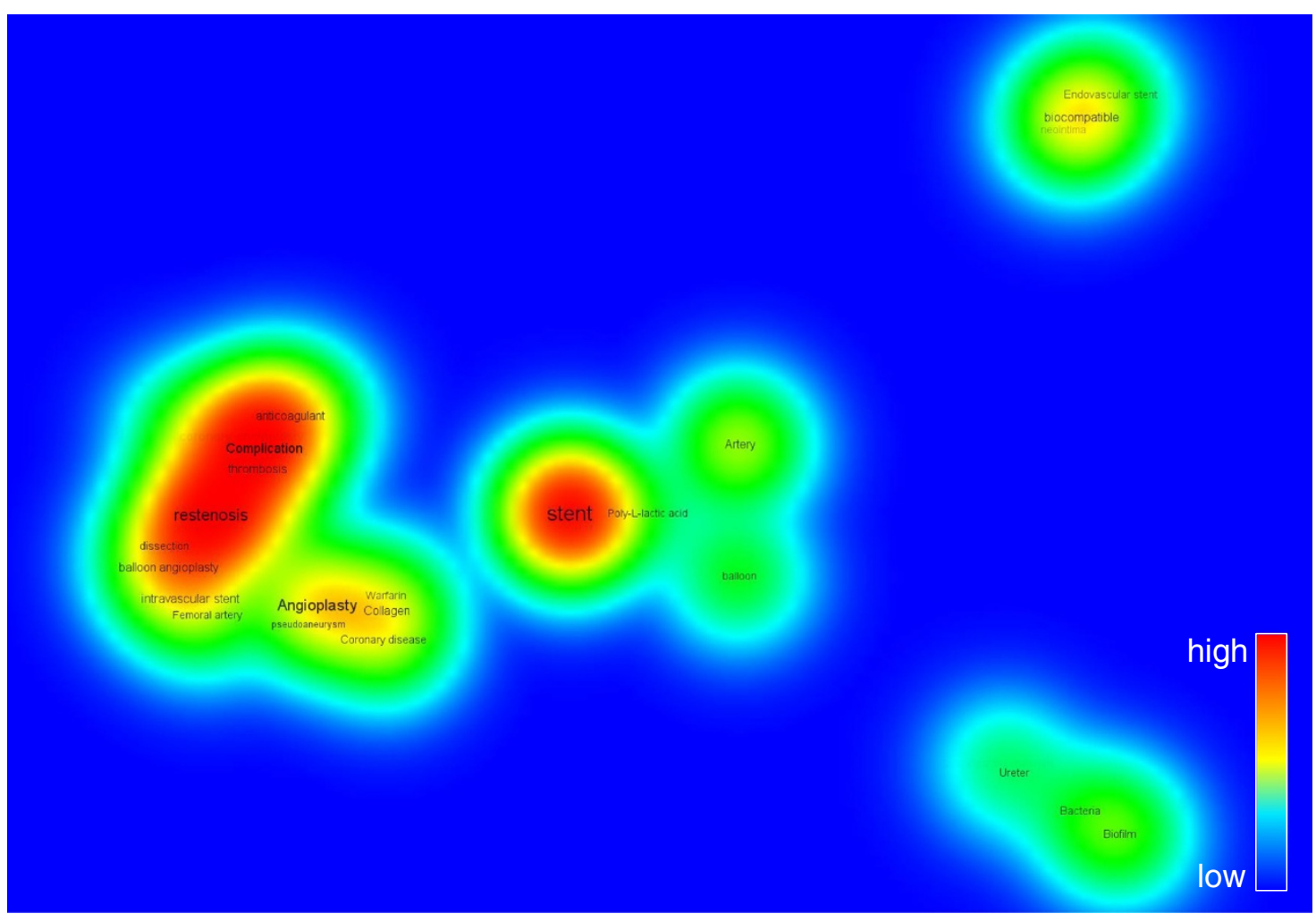

Figure 7 Density view of keyword map in Period I (1986 1995); the red color corresponds the highest density and the blue color corresponds the lowest density.

overcome the present limitations of stent such as thrombosis. These keywords network analysis results correspond to the previous reports on development of stent-related research [7].

\section{Conclusions}

Since the first stent was implanted in human coronary arteries by Puel and Sigwart in 1986, the advances of interventional treatment of coronary artery disease was remarkably progressed. It was results from the continuous development of the medical kits including stents, the accumulative experiences of operators and use of new antiplatelets [8]. Nowadays, stent coated with new polymeric drugs may have different activities in terms of affecting endothelium and vascular inflammation. Polymeric drug coating with NO-donors may decrease platelet adhesion and coagulation. Stent coated with polymeric CD34-antibodies may be able to prevent thrombosis by accelerating endothelial coverage and may capture circulating endothelial progenitor cells. Furthermore, development of biodegradable stents might also be useful way to decrease the incidence of late thrombosis on the stent. Anti-thrombotic therapy may be likely to be optimized with the development of more newly efficient anti-coagulant and anti-platelet drugs with a lower risk of bleeding complications $[9,10]$.

The research trends on stent for blood arteries are reviewed by bibliometric analysis using 7,790 journal articles of Web of Science database published from 1986 to 2013. We have applied the bibliometric indicators to analyze the journal article data, which contain simple number of publications for selecting key players, citation indicators for measuring qualitative research performance, collaboration indicators for figuring out the degree of international collaboration and keyword mapping for identifying the research trends. The stentrelated research has been performed in 71 countries including USA, Germany, Italy, etc. The countries at the forefront published many high-quality journal articles with strong international collaboration. The top-20 institutions such as Columbia University, Cardiovascular Research Foundation, Harvard University, etc. are also investigated as the core institutions on stent-related research. On the basis of the keyword network maps as time period, the research trends in a view of topic changing are finally explored. The topics such as 'drug eluting stent', 'stent coated with new polymers' and 'drug delivery systems' are prominent lately, which means lots of efforts are under way to overcome the 


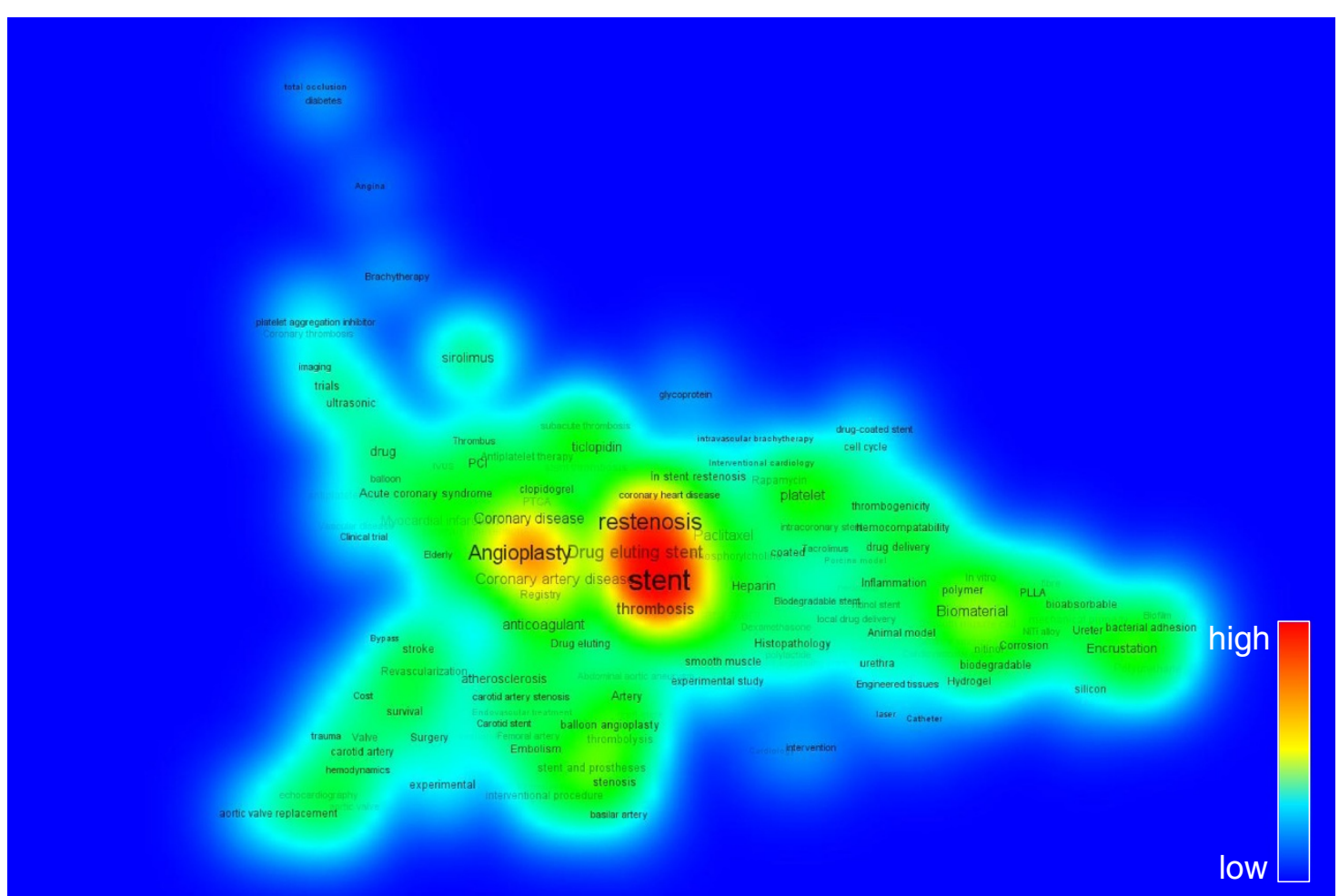

Figure 8 Density view of keyword map in Period II (1996 2005).

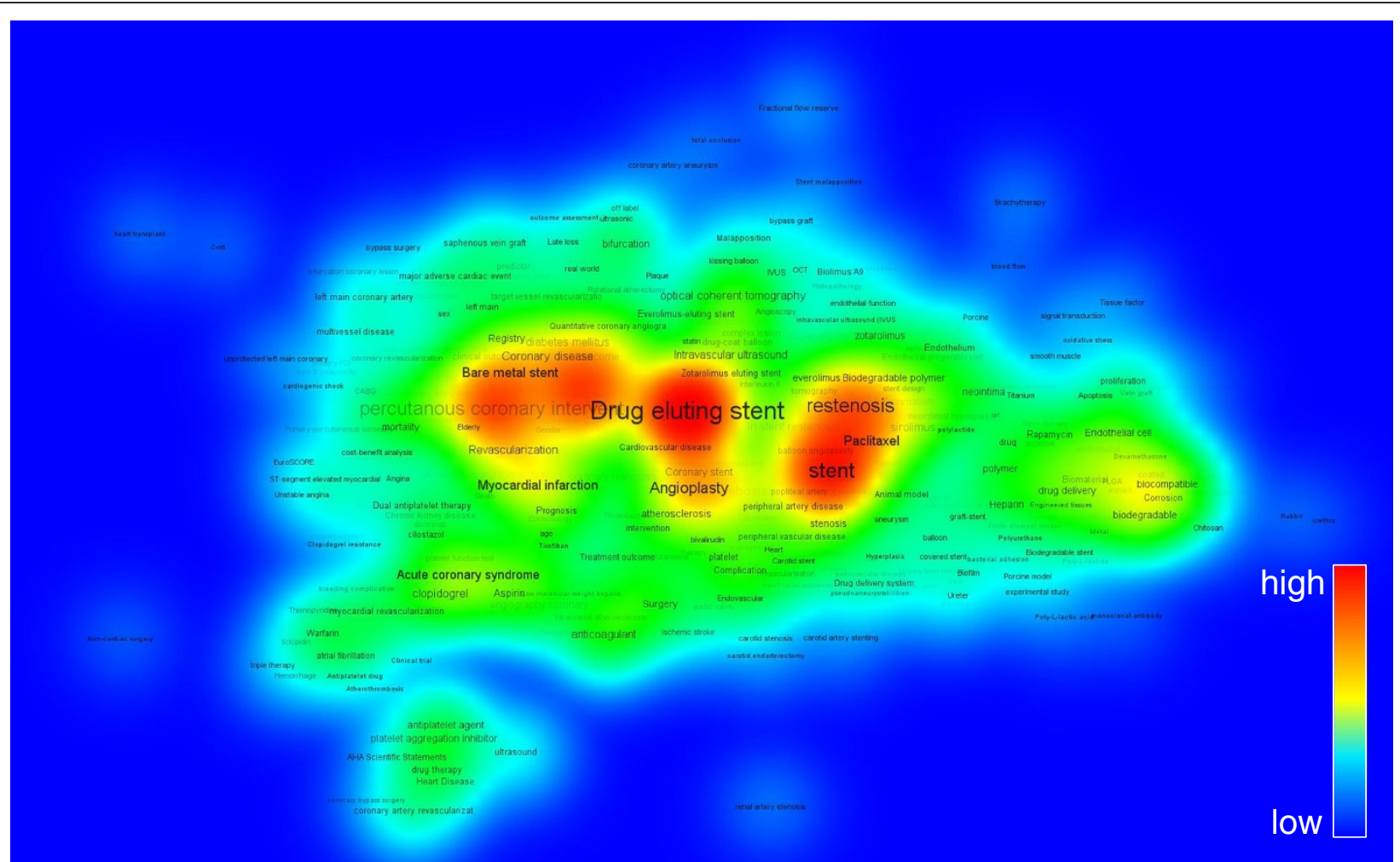

Figure 9 Density view of keyword map in Period III (2006 2013). 
present limitations of stent-related research such as thrombosis and polymeric drug coatings. The future of stent is expected to be more perspective on developing of innovative 'biodegradable/bioabsorbable' polymer and stents.

\section{Competing interests}

The authors declare that they have no competing interests.

\section{Authors' contributions}

SA carried out the bibliometric analysis, played the leading role of this study and drafted the manuscript. J-SS, BC, HK proposed the idea. YKS proposed the idea, carried out review and drafted the manuscript as a corresponding author. All authors read and approved the final manuscript.

\section{Acknowledgements}

Authors gratefully acknowledge the support of the Korea Institute for Science and Technology Information under the research program "Development of Exploring Support System on Global Future Technologies (K-14-L03-C01-S02)", "Development of emergence indicators based on journal-patent growth pattern analysis (K-14-L06-C07-S01)" and the Ministry of Science, ICT and Future Planning under the research program "ReSEAT Program (G-14-GM-IR05)".

\section{Author details}

${ }^{1}$ Technology Information Analysis Center, Korea Institute of Science and Technology Information, 66 Hoegi-ro, Seoul 130-741, Dongdaemun-gu, Korea. ${ }^{2}$ Department of Life Science, College of Biosystems, Dongguk University, Seoul 100-715, Korea. ${ }^{3}$ Noanix Corporation, 711 Sejung TechnoValley, 134 Gongdanro, Hoengdeok-gu, Chungju-si 361-290, Chungbuk, Korea. ${ }^{4}$ ReSEAT, Korea Institute of Science and Technology Information, 66 Hoegi-ro, Seoul 130-741, Dongdaemun-gu, Korea.

Received: 29 August 2014 Accepted: 5 October 2014

Published: 6 November 2014

\section{References}

1. Moses JW, Leon MB, Popma JJ, Fitzerald PJ, Holmes DR, O'Shaughnessy C, Caputo RP, Kereiakes DJ, Williams DO, Teirstein PS, Jaeger JL, Kuntz RE: Silorimus-eluting stents versus standard stents in patients with stenosis in a native coronary artery. N Engl J Med 2003, 349(14):1315-1323.

2. Morice MC, Serruyys PW, Sousa JE, Fajadet J, Ban HE, Perrin M, Colombo A, Schuler G, Barragan P, Guagliumi G, Molnar F, Falotico R: A randomized comparison of a sirolimus-eluting stent with a standard stent for coronary revascularization. N Engl J Med 2002, 346(23):1773-1780.

3. Bengisu $M$, Nekhili R: Forecasting emerging technologies with the aid of science and technology databases. Technol Forecast Soc Change 2006, 73:835-844.

4. Ryu JY: Dynamic Technology Level Evaluation Methodology and Forecasting based on Technology Growth Curve, Ph. D Thesis. KAIST; 2012.

5. Lee HJ, Kang JS, Goh BY: Bibliometric Indicators to identify Core Research Institutions in Green Technology (Dye-Sensitized Solar Cell). In Proceeding of Convergence Technology \& Information Convergence; 2009:95-102.

6. Van Eck NJ, Waltman L: Software survey: VOSviewer, a computer program for bibliometric mapping. Scientometrics 2010, 84(2):523-538.

7. Kim SJ, Park J-G, Kim JH, Kown IK: An overview of researches trend in drug-eluting stents development. Biomater Res 2010, 14(1):37-49.

8. Kim SH, Hong MK: Current status of drug-eluting stents. Korean J Med 2008, 75:370-382.

9. Eisenstein EL, Anstrom KJ, Kong DF, Shaw LK, Tuttle RH, Mark DB, Kramer JM, Harrington RA, Matchar DB, Kandzari DE, Peterson ED, Schulman KA, Califf RM: Clopidogrel use and long-term clinical outcomes after drug-eluting stent implantation. JAMA 2007, 297(2):159-168.
10. Bhatt DL, Fox KA, Hacke W, Berger PB, Black HR, Boden WE, Cacoub P, Cohen EA, Creager MA, Easton JD, Flather MD, Halffner SM, Hamm CW, Hankey GJ, Johnston SC, Mark KH, Mas JL, Montalescot G, Pearson TA, Steinhubl PG, Weber MA, Brennan DM, Fabry-Ribaudo L, Booth J, Topol EJ: Clopidogrel and aspirin versus aspirin alone for the prevention of atherothrombotic events. N Engl J Med 2006, 354(16):1706-1717.

doi:10.1186/2055-7124-18-17

Cite this article as: Ahn et al:: Recent trends on the stent research for blood arteries by bibliometric analysis. Biomaterials Research 2014 18:17.

\section{Submit your next manuscript to BioMed Central and take full advantage of:}

- Convenient online submission

- Thorough peer review

- No space constraints or color figure charges

- Immediate publication on acceptance

- Inclusion in PubMed, CAS, Scopus and Google Scholar

- Research which is freely available for redistribution 